\title{
Thyroid nodules in Iraq
}

\author{
H. M. Al-Hashimi \\ F.R.C.S.Ed. \\ Assistant Professor of Surgery, Department of Surgery, College of Medicine, \\ University of Baghdad, Baghdad, Iraq
}

\begin{abstract}
Summary
Two groups of patients with solitary thyroid nodules have been analysed. One hundred patients of the first group under 20 years of age were managed conservatively with supplementary doses of thyroxin. Three hundred and thirty patients of the second group over the age of $\mathbf{2 0}$ were treated surgically.

Seventeen percent of the first group had complete resolution of the thyroid nodule. The majority (eightythree patients) needed exploration for a residual lesion.

In the two groups, adenomatous goitre constituted the most frequent pathological finding. True adenoma was the next in frequency.

Malignant nodules were found in ten cases $(3.0 \%)$ of the second group; none was found in the first group. The overall incidence of carcinoma in solitary thyroid nodules in this study was $2 \cdot 3 \%$.
\end{abstract}

\section{Introduction}

Goitre is an endemic disease in Iraq. It has been shown by Caughey \& Follis (1965) and Demarchi et al. (1969) that the condition is due to lack of iodine in food and water.

The treatment of a solitary thyroid nodule is controversial and in spite of many contributions to the literature, there still exists a wide range of views on the mode of treatment. Sokal (1954) and Crile (1953) consider that the risks of malignant changes in a normal gland and a nodular goitre are equal. Astwood, Cassidy \& Aurbach (1960) advocated the treatment of thyroid nodules with thyroxin. Starr \& Goodwin (1958) used tri-iodothyronine for reducing the size of the goitre and the detection of thyroid carcinoma. Freeman (1963) adopted the policy of indiscriminate removal of thyroid nodules, aiming at the early detection of malignant disease. This discrepancy in the mode of treatment is largely due to the geographical variations in the incidence and aetiology of thyroid nodules in different parts of the world.

The purpose of this paper is to report the nature of solitary thyroid nodules in Iraq and to formulate some views on the condition. It is based on data of patients admitted to the University College Hospital of Baghdad and those treated in the follow-up clinic during the period $1960-70$, inclusive. In this paper, neither surgical detail not complications will be referred to.

\section{Material and methods}

During the 10-year period, two groups of patients with solitary thyroid nodule have been managed. They were patients proved, in 413 out of a total of 430 cases, to have solitary nodules at surgery and on histology. The first group were patients under the age of 20 years and the second group were patients over 20 . They were assessed by careful history-taking and clinical examination; an ENT examination, radiography of the chest and thyroid function tests, including radioactive iodine up-take, PBI, and scanning, were done in all cases.

The first group comprised 100 patients. The youngest was 6 months old and the oldest was 19 years. The sex ratio was $3: 1$ females to males. The chief complaint was of a lump in the neck, rarely causing symptoms. Radioactive ${ }^{131}$ I showed low $\mathrm{PB}^{131} \mathrm{I}$ in all the cases. Scanning revealed cold areas in $85 \%$ and was normal in the remaining $15 \%$.

The second group comprised 330 patients. They were admitted to the hospital for operative treatment or for diagnosis of the thyroid lump. The youngest patient was 20 years old, the oldest 70 years, with the average age around 40 years. The predominance of females over males in this group was of the order of $6: 1$. They presented mainly because of swelling in the neck. Dysphagia and pain were rarely complained of. A sensation of choking was not infrequently encountered. The known duration of the swelling was variable, ranging from 2 weeks to 20 years. Clinically, the majority of cases showed a well circumscribed lump, mobile on deglutition with a smooth surface and firm in consistency. The size was variable, ranging from less than a centimetre to several centimetres in diameter. Local tenderness was inversely related to the size of the swelling. Mild toxic symptoms were seen in four cases, fixity and hoarseness in two. Iodine studies showed low PBI and cold areas in the majority of cases (300), less commonly a low PBI and a normal scan, and in four cases a slightly raised PBI and hot areas in the scan. 
During the period covered by the analysis, a nonsurgical attitude had been taken for the first group of patients. They were kept on increasing doses of Eltroxin until tolerance was obtained for a 6-month period. Surgery was conducted when poor results were obtained. On the other hand, surgery was performed on the second group of patients irrespective of the size, the duration of the lump or the results of the scanning. Fixity with or without hoarseness was considered as an overt sign of malignancy.

\section{Results}

Taking the first group of patients, the results have been classified into three categories according to the degree of response to medical treatment. No response was obtained in fifty-nine cases, a slight response in twenty-four and complete resolution of the thyroid nodule in seventeen. Of the seventeen cases, seven had a normal scan and ten had a cold area in their scan. The eighty-three patients in the first and second categories were later explored and the diagnosis of a solitary thyroid nodule was confirmed. Histopathology showed adenomatous goitre in seventy cases, foetal adenoma in ten and solitary cysts in three. No malignant nodule was found.

Of the 330 nodules in the second group of patients who were treated surgically, 260 proved to be adenomatous goitre; in approximately one-third of them hyperplastic changes were seen. Eighteen were solitary cysts, thirty-seven were true adenomas (twenty-four were foetal, ten were macrofollicular, and three were Hürthle adenomas). Ten cases $(3.03 \%)$ were carcinoma. Two were foci of Hashimoto's disease and one showed subacute thyroiditis. Two cases were hydatid cysts. The types of carcinoma encountered in this series were papillary in eight cases and follicular in two.

\section{Discussion}

Throughout this paper, the Meissner \& Warren (1969) classification has been adopted. It emphasizes that true adenoma is neoplastic in nature, while adenomatous goitre (endemic goitre) is actually the result of either excessive colloid storage or a compensatory formation of new follicles.

In this series, adenomatous solitary nodules were the commonest pathology in the first and second groups of patients. The true adenomas were the less common, while the malignant nodules were the least. This is consistent with Shukri's (1967) findings. The predominance of adenomatous goitre in this series is readily explained by the wide prevalence of iodine-deficiency goitre in this country.

Wide variations in the incidence of malignant nodules have been reported. Freeman (1963) reported a rate of $17 \cdot 7 \%$. Taylor (1969) reported a rate of $12.6 \%$. In our series, no malignant nodules were found in the first group and only ten cases $(3.03 \%)$ in the second group of patients, making an overall incidence of $2.3 \%$.

Pre-operative diagnosis of whether or not a nodule is malignant is difficult. In two cases there was no difficulty in making the diagnosis of malignant nodules on clinical grounds because of the presence of overt signs of malignancy. In the remaining eight cases, there was little clinical variation between benign and malignant lesions.

Scanning of a thyroid harbouring a nodule is a helpful procedure in the diagnosis. Even so, it is not by any means decisive.

In our series, we have found that cold nodules are benign rather than being malignant. In the first group of patients, eighty cases showed cold areas in the scan, yet none of these proved malignant. In the second group, 300 out of 330 cases showed cold areas and only ten cases proved malignant.

Hot nodules have not been encountered in the first group of patients. In the second group, only four cases with mild toxic symptoms were reported which proved benign on histology. This agrees well with the findings of Green (1957), although malignant hot nodules have been recorded by Meadows (1961) and others.

Localized forms of Hashimoto's disease in two cases and thyroiditis in one case presenting as solitary thyroid nodules have been reported. The diagnosis was made on histopathology after surgery. The operation would have been avoided by more refined investigations.

Owing to the immense number of teen-aged patients with thyroid nodules, we were encouraged to adopt medical treatment as a first line in the management. Surgery was adopted in the unresponding cases of the first group and all cases of the second group, as it is the only way to ascertain the nature of the thyroid lump and to obviate the risk of underlying malignancy. No malignant nodules were found among the first group of patients. This proves that the policy of indiscriminate removal of thyroid nodules (Freeman, 1963) in very young patients is rather an aggressive one. Hydatid disease, being rather prevalent in Iraq, was encountered in two cases of the second group presenting as solitary thyroid nodule.

\section{Conclusions}

(1) In a goitrous district like Iraq, the benign nature of thyroid nodules is striking.

(2) The iodine-deficiency nodule is by far the commonest type encountered.

(3) The overall incidence of malignant nodules in this series was $2 \cdot 3 \%$. This is because of the high incidence of iodine-deficiency nodules. 
(4) Figures of malignant nodules from nongoitrous districts should never be quoted for goitrous districts.

\section{References}

Astwood, E.B., Cassidy, C.E. \& Aurbach, G.D. (1960) Treatment of goitre and thyroid nodules with thyroxin. Journal of the American Medical Association, 174, 459.

CAUghey, J.E. \& Follis R.H. JR (1965) Endemic goitre and iodine malnutrition in Iraq. Lancet, $\mathbf{i}, 1032$.

CrILE, G. (1953) Adenoma and carcinoma of the thyroid gland. New England Journal of Medicine, 249, 586.

Demarchi, M., Al-Hindawi, A., Abdulnabi, M. \& TajelDIN, H. (1969) Prevalence and etiology of goitre in Iraq. American Journal of Nutrition, 22, 1660.

FreEman, G.C. (1963) The management of the thyroid nodule. Surgical Clinics of North America, 43, 1363.
GreEN, R. (1957) Discrete nodules of the thyroid gland, with special reference to carcinoma. Annals of the Royal College of Surgeons, 21, 73.

Meadows, P.M. (1961) Scintillation scanning in the management of the clinically single thyroid nodule. Journal of the American Medical Association, 177, 229.

Meissner, W.A. \& WARRen, S. (1969) Tumours of the Thyroid Gland, p. 30. Armed Forces Institute of Pathology, Washington, D.C.

SHUKRI, A.M. (1967) The solitary thyroid nodule in Iraq British Journal of Clinical Practice, 21, 75.

SOKAL, J.E. (1954) Surgical statistics on malignant goitre. Surgery, Gynecology and Obstetrics, 99, 108.

STARR, P. \& Goodwin, W. (1958) Use of tri-iodothyronin for reduction of goitre and detection of thyroid cancer. Metabolism, 7, 287.

TAYLOR, S. (1969) The solitary thyroid nodule. Journal of the Royal College of Surgeons of Edinburgh, 14, 267. 